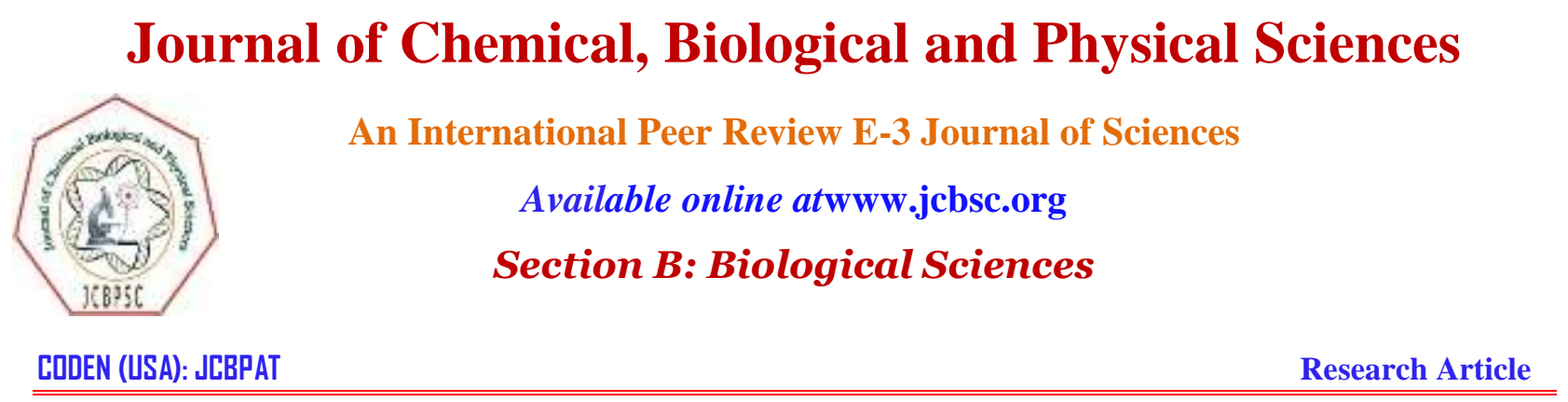

\title{
Effect of Temperature Regimes on Seed Germination and Agronomic Features at Early Growth stage of Wheat (Triticum aestivum L.) cultivars
}

\author{
Nafisa Khaskheli ${ }^{1}$, Ghulam Mustafa Laghari ${ }^{1}$, Sajid Hussain², Maqsood Ahmed \\ Khaskheli1 $^{1,2}$, Abdul Hafeez Laghari ${ }^{1,3}$, Mahmooda Buriro', Anab Khanzada ${ }^{1,4}$ Fahad Ali \\ Kalhoro $^{2}$ \\ ${ }^{1}$ Department of Agronomy, Sindh Agriculture University, Tandojam, 70060, Hyderabad, \\ Sindh, Pakistan \\ ${ }^{2}$ State Key Laboratory of Rice Biology, China National Rice Research Institute, Hangzhou, \\ 311400, Zhejiang, China \\ ${ }^{3}$ State Key Laboratory of Cotton Biology, Institute of Cotton Research, Anyang, 455000, \\ Henan, China \\ ${ }^{4}$ Key Laboratory of Crop Physiology, Ecology and Production, Ministry of Agriculture, \\ Nanjing Agricultural University, Jiangsu, 210095, China
}

Received: 21 September 2019; Revised: 27 September 2019; Accepted: 05 October 2019

\begin{abstract}
High temperature is an important global issue which hindered the agricultural production, especially wheat (Triticum aestivum L.) crop. Many studies have been done to check the effect of temperature on wheat grain filling. However, Effect of temperature regimes on seed germination and seedling establishment of wheat cultivars has not been studied. For this purpose, the experiment was conducted at Seed Testing Laboratory, Department of Agronomy, Sindh Agriculture University, Tandojam during the year
\end{abstract}


wheat season 2017. Completely Randomize Design (CRD) were used with three wheat cultivars (TD-1, Sattar, and Sahar) as planting material and three temperature regimes (15 ${ }^{\circ} \mathrm{C}, 20{ }^{\circ} \mathrm{C}$, and $25^{\circ} \mathrm{C}$ ) with three replication. The results showed that, at 15,20 , and $25^{\circ} \mathrm{C}$ temperature, the maximum seed germination $(81.3,65.3$, and $62 \%)$, shoot length $(18.2$, $13.8,7.5 \mathrm{~cm})$, root length $(10.6,7.9$, and $5.6 \mathrm{~cm})$, shoot fresh weight $(764.0,881.3$, and $578.3 \mathrm{mg})$, root fresh weight $(976.7,639.3,501.0 \mathrm{mg})$, shoot dry weight $(68.0,62.0$, and $40.3 \mathrm{mg}$ ), root dry weight $(70.7,61,45 \mathrm{mg})$, root moisture contents $(58.7,46.3$, and 46.3 $\%)$, and shoot moisture $(81.7,77.7$, and $77.7 \%)$ respectively. As for as cultivars are concerned, the above mentioned parameters were recorded as $(72.3,68.3$, and $68 \%)$, $(13.5,13.1$, and $12.9 \mathrm{~cm}),(8.6,7.8$, and $7.7 \mathrm{~cm}),(836.7,625.3$, and $781.7 \mathrm{mg}),(674.0$, 818.0 , and $605.0 \mathrm{mg}),(62.3,55.3$, and $52.7 \mathrm{mg}),(61.3,58.0$, and $56.3 \mathrm{mg}),(58.0,49.7$, and $43.0 \%)$, and $(90.3,75.3,66.7 \%)$ in cultivars TD-1, Sattar, and Sahar respectively. It was concluded that among temperatures $15{ }^{\circ} \mathrm{C}$ produced maximum all the growth and yield traits studied as compared other temperatures. Among cultivars, TD-1 gave better results as compared to other wheat cultivars.

Key words: Temperature regimes, Seed germination, Seedling growth, Wheat cultivars

\section{INTRODUCTION}

Wheat (Triticum aestivum L.) belongs to Poaceae family and is cultivated worldwide. Wheat has $30 \%$ contribution in world grain production and 50\% world's grain trade. It is also reported that, the world need to produce about 198 million tones more wheat to feed the world population till 2050 (FAO), and this need to be increased about $77 \%$ in developing countries such as Pakistan ${ }^{1}$. Wheat and is also a vital cereal crop and taken as a staple food in Pakistan, and its consumption is in various form from daily bread usage to other products in different ways in Pakistan and rest of the world. Wheat crop is considering the staple food crop of most of the humans, it is cultivated in the major area of the irrigated land than other crops and contributing an essential role in the economy of the countries. The growth and production could be increased as crop sown at the appropriate time and maintain the optimum moisture level to improve germination, growth, and input use efficiency ${ }^{2}$. However, as it is critical meals crop grown during the frostiness season, and cultivated in different agro-climate zones of the arena ${ }^{3,4}$. Moreover, the current wheat yield is not matching the real potential of yield cultivars due to many reasons. These reasons could be genetic makeup, biotic, and abiotic stresses, especially temperature ${ }^{3}$.

It is well reported the role of temperature on plant growth and development 5 . High temperature negatively affects the plant physiology such as photosynthetic membranes (thylakoids) and reduction of chlorophyll contents, photosynthetic leaf, abortion of embryo, grain filling rate, and grain yield ${ }^{6}$. Along with physiological traits, temperature also affects the metabolism and protein synthesis ${ }^{7}$. The excessive temperature in conjugation with drought poses the maximum vital environmental constraint to plant survival and crop productivity. Multiplied temperature and drought carried out before grain filling shortened the grain filling and grain weight ${ }^{8}$.

Keeping in view this bundle of information regarding the temperature issue, this study was conducted to evaluate the appropriate temperature for the seedling establishment of wheat cultivars. The main objectives of this study were; (i) to assess the impact of different temperature regimes on the germination 
of wheat cultivars, (ii) to find out suitable temperature and screen out the best wheat cultivar for better growth and seedling establishment.

\section{MATERIALS AND METHODS}

Research design and treatment plan: A pot culture experiment was performed at 'Seed Testing Laboratory, Department of Agronomy, Sindh Agriculture University (SAU) Tandojam, Sindh, Pakistan during the Rabi season 2017-2018. Three wheat cultivars such as TD-1, Sattar, and Sahar were used as planting material. The experiment was laid out under a completely randomized design (CRD) with the factorial arrangement with three replications. The experiment was divided into two factors (A-B), factor A has the three different temperature regimes, i.e., $15{ }^{\circ} \mathrm{C}, 20{ }^{\circ} \mathrm{C}$, and $25{ }^{\circ} \mathrm{C}$, and the factor $\mathrm{B}$ has three different wheat cultivars viz. TD-1, Sattar, and Sahar. The seed of all cultivars was collected from the wheat research section, of Agriculture Research Institute (ARI) Tandojam.

Experiment Material, Soil and Fertilizer Management: The seeds were grown in the plastic boxes, and the size of each box was $30 \mathrm{~cm}$ in width, $50 \mathrm{~cm}$ in length, and the total area of each box was $30 \times 50 \mathrm{~cm} 2$. Each plastic box was filled with $3 \mathrm{~kg}$ sandy loam soil having EC $0.49 \mathrm{dS} \mathrm{m}{ }^{-1}, \mathrm{pH} \mathrm{8.1}$, and organic matter $0.8 \%$. Further, organic and inorganic fertilizers such as Nitrogen $(\mathrm{N})$, Phosphorus $(\mathrm{P})$, Potassium $(\mathrm{K})$ and Farm Yard Manure (FYM) as per recommended doses were applied. The P, K, and FYM were mixed with soil before fill-up the boxes and the $\mathrm{N}$ were also applied at the time of first watering as per recommended dose, and further irrigations were applied irrigated water according to the requirement of the crop. All essential nutrient elements were applied in the following forms $\mathrm{N}$ in the form of (Urea) $\mathrm{P}$ in the form of di-ammonium phosphate (DAP), and $\mathrm{K}$ in the form of sulphate of potash (SOP) respectively.

Seed Treatment and Seed Sowing Activity: About 100 -150 healthy and fresh disease-free seeds from the each wheat cultivars were taken and were transferred separately into $100 \mathrm{~mL}$ glass beaker and tagged the label according to the cultivar, later washed the seeds twice with water. After washing the seeds 40 $\mathrm{mL}$ of $(3 \%)$ Potassium hypochlorite solution was added and placed the seeds for 10 minutes, and thoroughly washed the seeds 3 to 4 times with water. The seeds were sown in the previously moist plastic boxes with three rows, and each row had five holes. The holes were made by using single hand dibbler. About five seeds/plants throughout the experiment were sown in each hole. After the completion of the seed sowing process, the boxes were placed under three different temperature control growth chamber according to the temperature regimes and modified the photoperiod cycle and moisture level according to the crop requirement.

Observations and data collection: The following characteristics were observed from the different wheat cultivars at the various temperature ranges under the laboratory condition i.e. Seed germination (\%), Shoot length $(\mathrm{cm})$, Root length $(\mathrm{cm})$, Shoot fresh weight $(\mathrm{mg})$, Root fresh weight $(\mathrm{mg})$, Shoot dry weight $(\mathrm{mg})$, Root dry weight (mg), Root moisture (\%), Shoot moisture (\%), Seed germination till the end of the harvesting.

$$
\begin{aligned}
& \text { Seed germination }(\%)=\frac{\text { Number of germinated seeds }}{\text { Total number of seeds }} \times 100 \\
& \text { Root moisture }(\%)=\frac{\text { Root fresh weight }}{\text { Root dry weight }} \times 100
\end{aligned}
$$




$$
\text { Shoot moisture }(\%)=\frac{\text { Shoot fresh weight }}{\text { Shoot dry weight }} \times 100
$$

The seed germination percentage was recorded after seven days of sowing. After completion of germination of the seed, the germinated seedlings were protected from recording the root and shoot length of the seedlings under different treatments. Moreover, the fresh weight of seedlings were recorded, and after completion of the observations on fresh biomass of the seedlings, the seedlings were kept in the oven at $50{ }^{\circ} \mathrm{C}$ for drying. After drying of the seedlings, dry weight was determined.

Statistical analysis: The collected data were statistically analyzed by using the computer statistical program student edition of statistics version 8.1 (copyright, 1996. Analytical software, USA) with two way-ANOVA was applied to compare treatment means.

\section{RESULTS}

The experiment was conducted to assess the effect of temperature on seed germination and seedling growth of wheat cultivars. Three wheat cultivars (TD-1, Sattar, and Sahar) were evaluated for their performance against three different temperatures as $15{ }^{\circ} \mathrm{C}, 20{ }^{\circ} \mathrm{C}$, and $25{ }^{\circ} \mathrm{C}$. The observations were recorded as seed germination $(\%)$, shoot length $(\mathrm{cm})$, root length $(\mathrm{cm})$, shoot fresh weight $(\mathrm{mg})$ root fresh weight (mg), shoot dry weight (mg), root dry weight (mg), root moisture (\%) and shoot moisture (\%). The data on the above characters are presented in Figures (1-9).

Seed germination percentage (SG \%): The statistical examination showed that the Seed germination percentage ( $\mathrm{SG} \%$ ) of different wheat cultivars significantly differed at $\mathrm{P}<0.05$ including the various temperature regimes along with the collaborative impact of temperature regimes on wheat cultivars Figure (1).

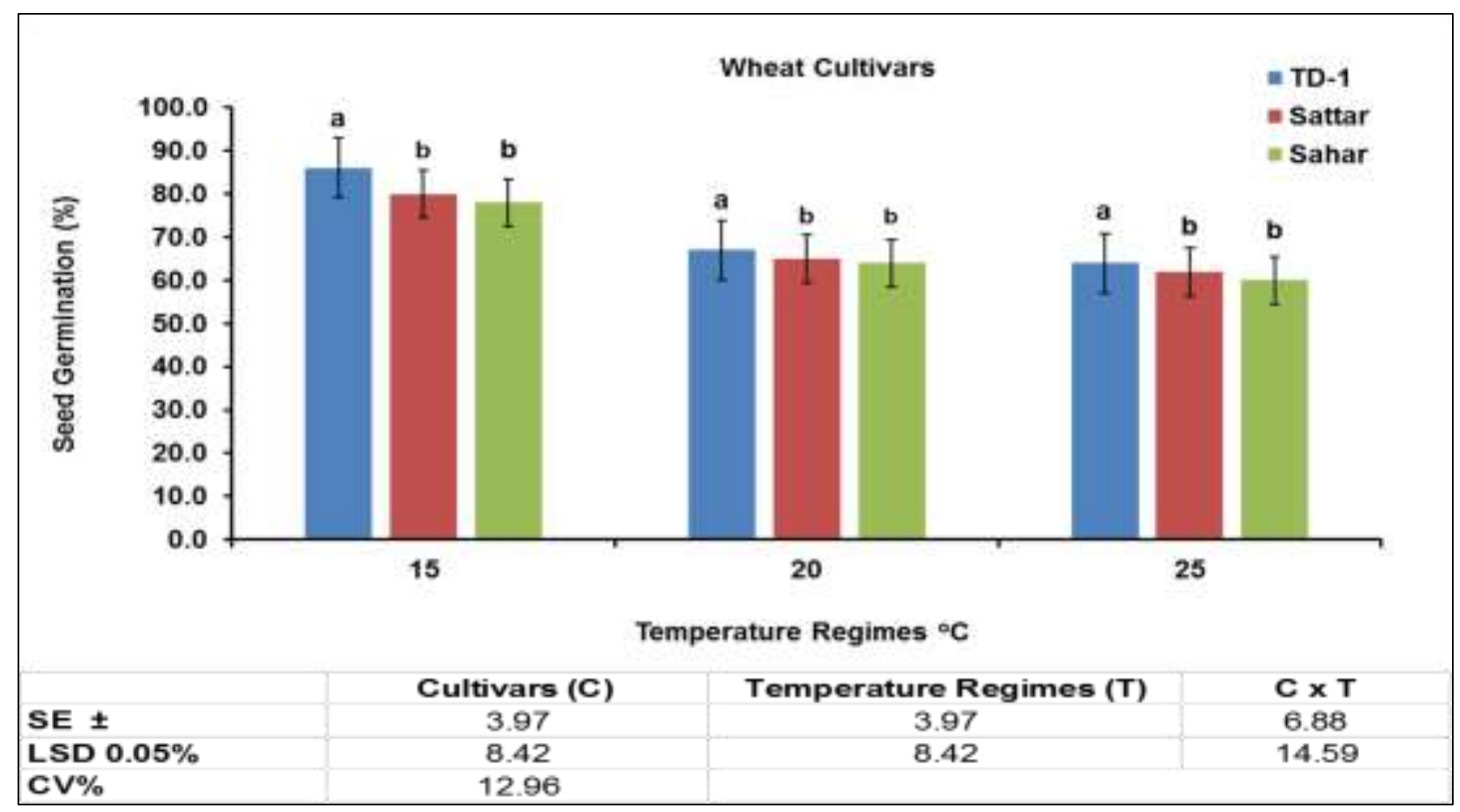

Fig.1: Seed germination (\%) of wheat cultivars as affected by different temperature regimes. Where TD1, Sattar, and Sahar are wheat cultivars and 15,20 , and $25^{\circ} \mathrm{C}$ are temperature regimes. 
The results displayed that the wheat cultivar TD-1 showed the significant results with mean values of seed germination $86.0 \%\left(15^{\circ} \mathrm{C}\right), 67.0 \%\left(20^{\circ} \mathrm{C}\right)$, and $64.0 \%\left(25^{\circ} \mathrm{C}\right)$ were recorded respectively. Followed by the satisfactory seed germination mean values with $(80.0,65.0$, and $62.0 \%)$ were noted into the wheat cultivar Sattar at the same temperature regimes 15, 20 and $25{ }^{\circ} \mathrm{C}$ respectively. However, the lowermost seed germination means values with $(78.0,64.0$ and $60.0 \%)$ were studied in the Sahar wheat cultivar at the 15,20 and $25^{\circ} \mathrm{C}$ temperature regimes separately.

Shoot length $(\mathbf{c m})$ : The consequences for shoot length in $(\mathrm{cm})$ as affected by the different temperature regimes on the various wheat cultivars as displayed in Figure $(2)$. The shoot length $(\mathrm{cm})$ of different wheat cultivars significantly differed at $\mathrm{P}<0.05$ with the various temperature regimes accompanied by the interactive impact of wheat cultivars with temperature regimes. The results indicated that the wheat cultivar TD-1 performed better results with the higher mean values of shoot length (19.1, 14.2 and 8.2 $\mathrm{cm}$ ) were recorded at the 15,20 and $25{ }^{\circ} \mathrm{C}$ temperature regimes, However the appropriate shoot length mean values with the $(18.2,14.1$ and $7.1 \mathrm{~cm})$ was documented in the wheat cultivar Sattar at the same temperature regimes respectively. While at the 15,20 and $25{ }^{\circ} \mathrm{C}$ temperature regimes minimal seed germination mean values with $(17.3,13.2$ and $6.9 \mathrm{~cm})$ were recorded in the Sahar wheat cultivar.

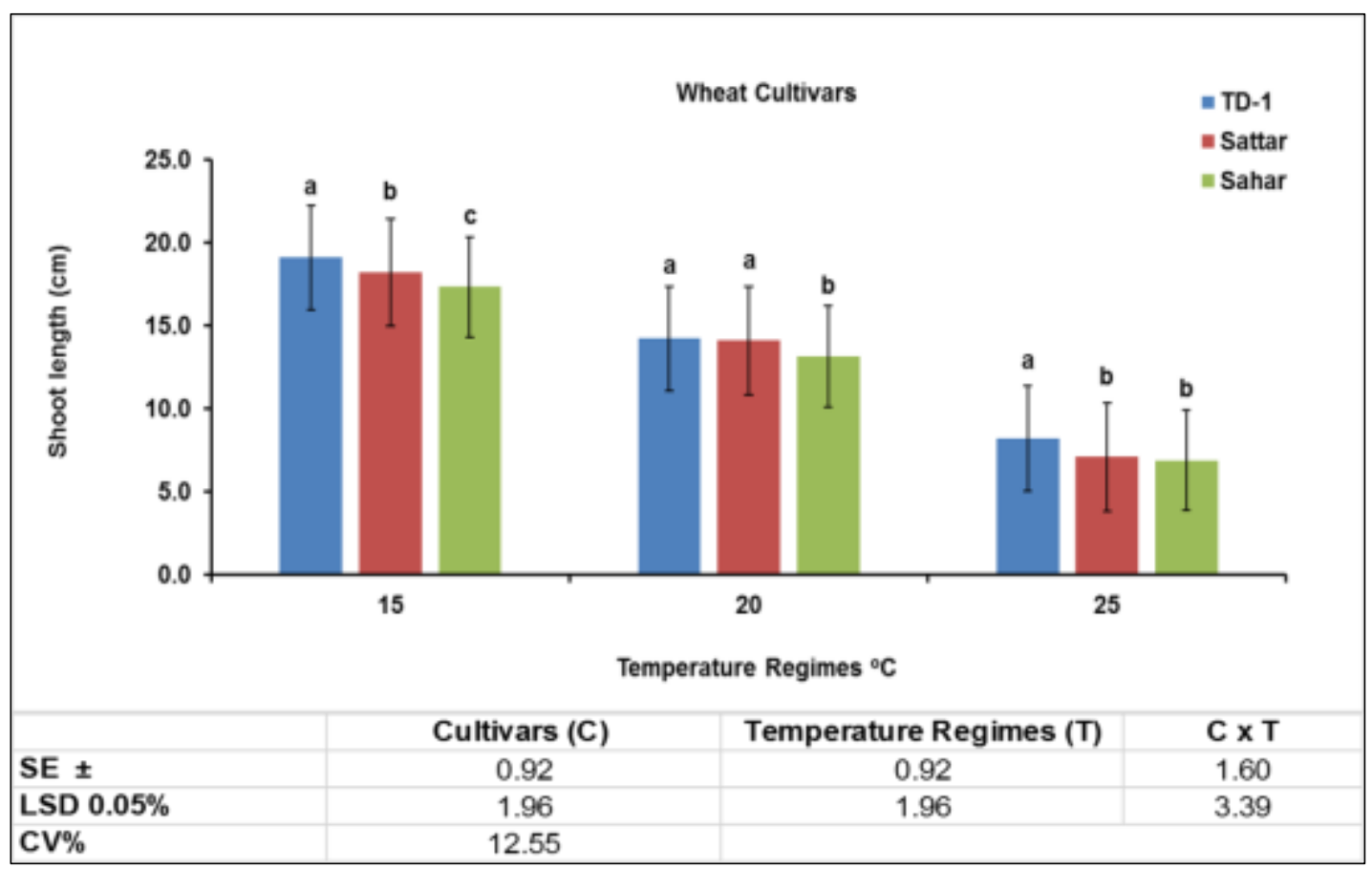

Fig.2: Shoot length $(\mathrm{cm})$ of wheat cultivars as affected by different temperature regimes. Where TD-1, Sattar, and Sahar are wheat cultivars and 15,20 , and $25^{\circ} \mathrm{C}$ are temperature regimes.

Root length $(\mathbf{c m})$ : The root length $(\mathrm{cm})$ of different wheat cultivars significantly altered at the $(0.05 \%)$ probability level, together with diverse temperature regimes along with the associative influence of wheat cultivars as well as the temperature regimes were also measured Figure (3). The outcomes specified that there was a significant difference between different wheat cultivars. According to the results, the maximum mean values of root length $(\mathrm{cm})$ were revealed as $(11.3,8.3$ and $6.3 \mathrm{~cm})$ in the wheat cultivar 
TD-1 on the contrasting temperature 15,20 and $25{ }^{\circ} \mathrm{C}$ regimes respectively. In addition, followed by the reasonable results of the root length mean values with $(10.3,7.8$ and $5.3 \mathrm{~cm})$ were notified in the wheat cultivar Sattar at the same temperature regimes collectively. Conversely, the un-sufficient mean values in case of root length $(\mathrm{cm})$ of wheat cultivar Sahar with $(10.2,7.8$ and $5.2 \mathrm{~cm})$ were reported at the following 15,20 and $25^{\circ} \mathrm{C}$ temperature regimes objectively.

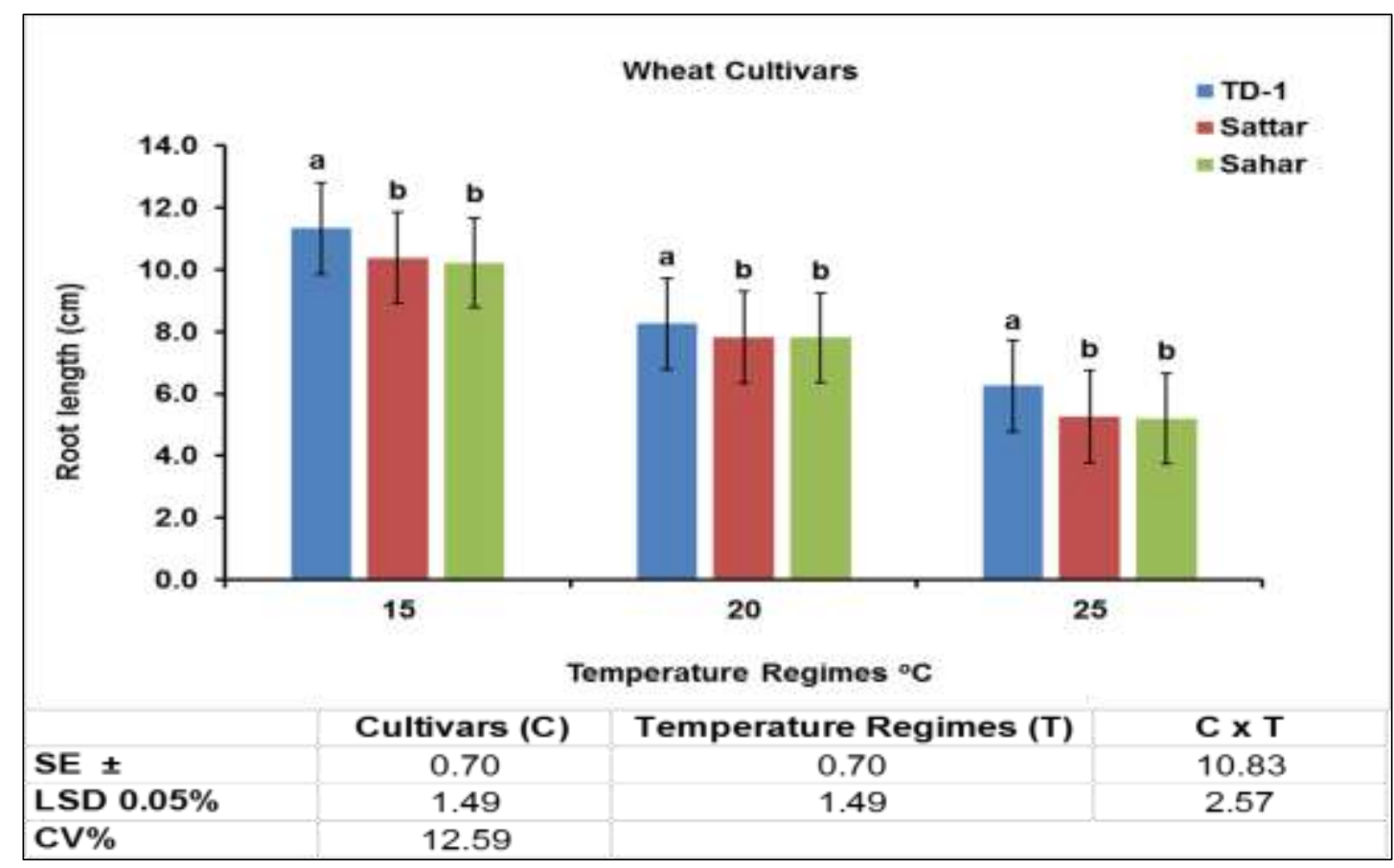

Fig.3: Root length $(\mathrm{cm})$ of wheat cultivars as affected by different temperature regimes. Where TD-1, Sattar, and Sahar are wheat cultivars and 15,20 , and $25^{\circ} \mathrm{C}$ are temperature regimes.

Shoot fresh weight (mg): The results for fresh shoot weight (mg) as affected by different temperature on wheat cultivars presented in Figure (4). The statistical investigation was declared that the fresh shoot weight $(\mathrm{mg})$ of various wheat cultivars were significantly varied at $(\mathrm{P}<0.05)$ also collectively the different temperature regimes along with collaborative effects of wheat cultivars among the various temperature regimes were similarly found statistically significant at $(\mathrm{P}<0.05)$. The results specified that the maximum average mean value for $(1025.0,994.0$ and $625.0 \mathrm{mg}$ ) fresh shoot weight were documented within the wheat cultivar TD-1 at the following different temperature 15,20 and $25{ }^{\circ} \mathrm{C}$ regimes correspondingly. While the following average mean values, i.e. $(995.0,860.0$ and $570.0 \mathrm{mg}$ ) of fresh shoot weight were moderately detected in wheat cultivar Sattar at the same temperature regimes. Whereas the maximum average means values such as $(910.0,790.0$ and $560.0 \mathrm{mg})$ of fresh shoot weight were confirmed in cultivar Sahar at the both 15,20 and $25^{\circ} \mathrm{C}$ temperature regimes. 


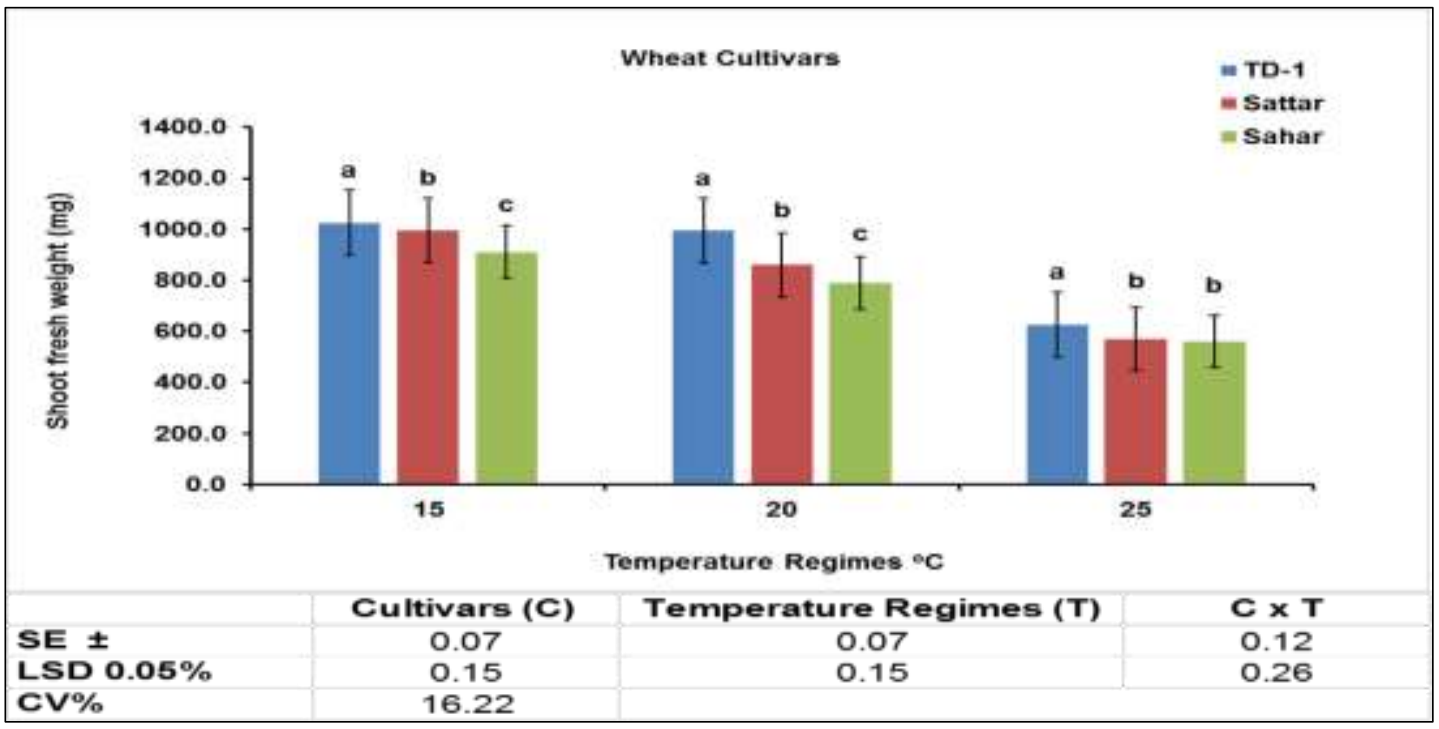

Fig.4: Shoot fresh weight $(\mathrm{mg})$ of wheat cultivars as affected by different temperature regimes. Where TD-1, Sattar, and Sahar are wheat cultivars and 15,20 , and $25^{\circ} \mathrm{C}$ are temperature regimes.

Root fresh weight (mg): Similarly, the result values displayed that the fresh root weight (mg) of wheat cultivars as influenced by the different temperature regimes were presented in Figure (5). The statistical exploration confirmed that the fresh shoot weights $(\mathrm{mg})$ of various wheat cultivars were significantly varied at $\mathrm{P}<0.05$ level at different temperature regimes.

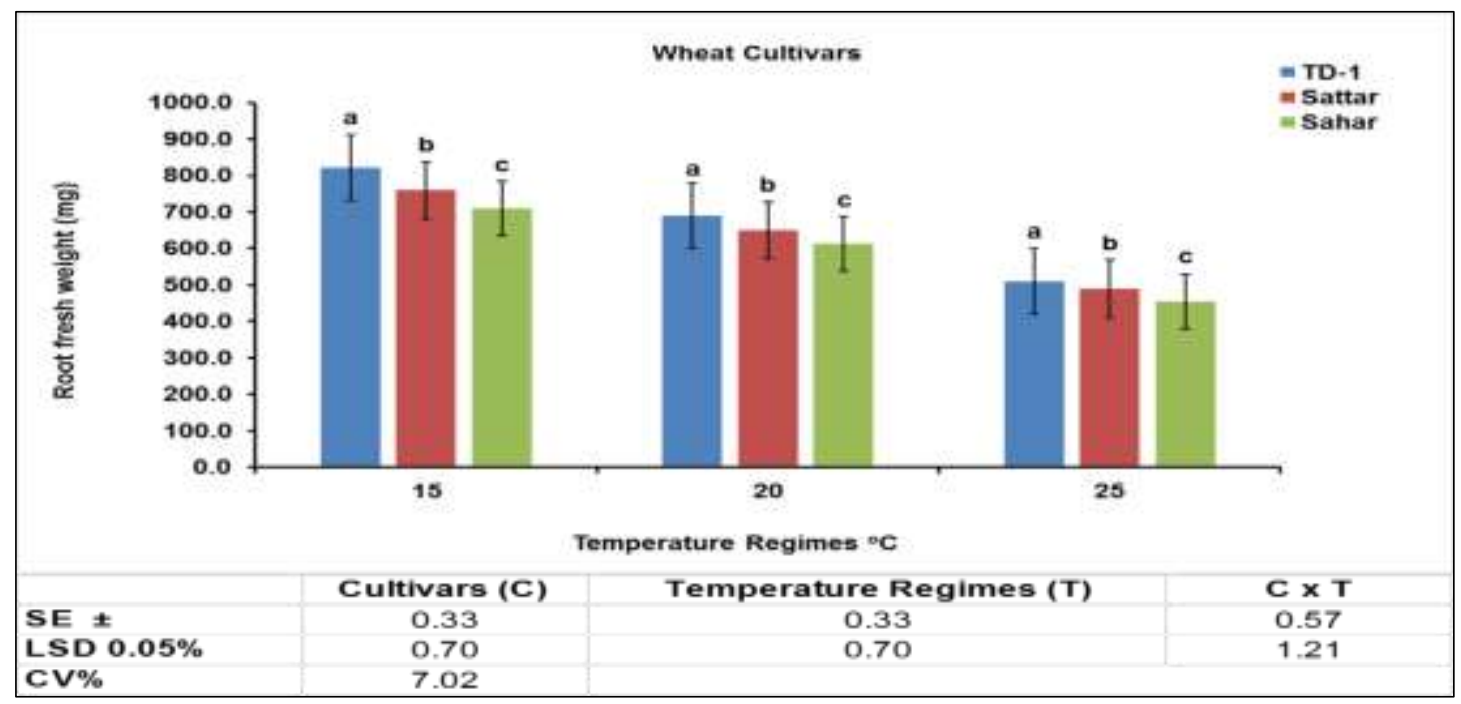

Fig.5: Root fresh weight (mg) of wheat cultivars as affected by different temperature regimes. Where TD1, Sattar, and Sahar are wheat cultivars and 15,20 , and $25^{\circ} \mathrm{C}$ are temperature regimes.

The investigation exhibited that at the various temperature 15,20 and $25{ }^{\circ} \mathrm{C}$ regimes, relatively enhanced root fresh weight with maximum average mean values $(822.0,690.0$ and $510.0 \mathrm{mg})$ was noted under the TD-1 wheat cultivar specifically; whereas the satisfactorily results of the root fresh weight (mg) average 
mean values as $(760.0,650.0$ and $490.0 \mathrm{mg})$ were reported under same temperature levels in case of the wheat cultivar Sattar. Additionally, in the Sahar wheat cultivar, the temperature regimes showed the minimum root fresh weight with following $(710.0,613.0$ and $455.0 \mathrm{mg}$ ) average mean values were investigated by the 15,20 and $25{ }^{\circ} \mathrm{C}$ temperature regimes respectively.

Shoot dry weight (mg): The experiment findings for dry shoot weight (mg) of different wheat cultivars as influenced by the distinctive temperatures regimes displayed in Figure (6) together with the statistical analysis of different wheat cultivars, temperature regimes along with their interactive effects were also detected to be statistically significant at the level of probability $0.05 \%$. The results showed that the highest average mean values for shoot dry weight with $(78.0,64.0$ and $45.0 \mathrm{mg}$ ) were confirmed in the wheat cultivar TD- 1 at the 15,20 and $25^{\circ} \mathrm{C}$ temperature regimes respectively. While in the wheat cultivar Sattar was founded moderately shoot dry weight average mean values as $(64.0,62.0$ and $40.0 \mathrm{mg}) \mathrm{in}$ the temperature regimes 15, 20 and $25{ }^{\circ} \mathrm{C}$ respectively. Furthermore among the varietal performance, including the various temperature regimes as well as in the collaborative effect were studied smallest average mean values for shoot dry weight with $(62.0,60.0$ and $36.0 \mathrm{mg})$ in wheat cultivar Sahar at the following 15,20 and $25^{\circ} \mathrm{C}$ temperature regimes respectively.

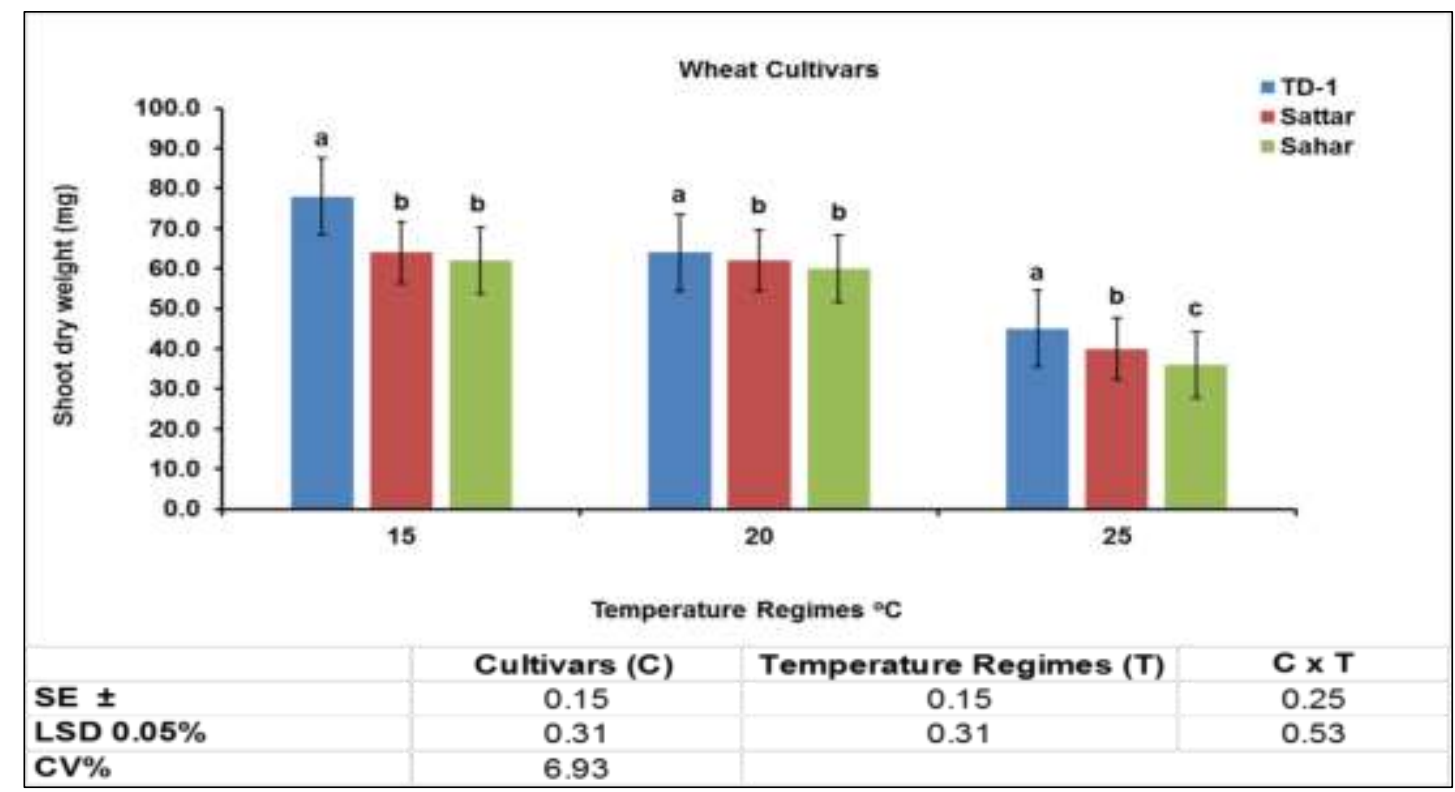

Fig.6: Shoot dry weight $(\mathrm{mg})$ of wheat cultivars as affected by different temperature regimes. Where TD1, Sattar, and Sahar are wheat cultivars and 15,20 , and $25^{\circ} \mathrm{C}$ are temperature regimes.

Root dry weight (mg): The results for root dry weight (mg) of various wheat cultivars as affected by the individual temperature regimes presented in the Figure (7). The temperature regimes accompanied by the interactive effects were also identified to be statistically significant at the $0.05 \%$ probability level. The significance of the results revealed that the highest average mean values with (74.0, 65.0 and $48.0 \mathrm{mg}$ ) for root dry weight were confirmed at 15,20 and $25{ }^{\circ} \mathrm{C}$ temperature regimes respectively in the wheat cultivar TD-1. In addition, the wheat cultivar Sattar was performed sufficiently with the average mean values (70.0, 60.0 and $44.0 \mathrm{mg}$ ) root dry weight was reported at the all temperature regimes 15, 20 and 25 ${ }^{\circ} \mathrm{C}$ temperature regimes respectively. Moreover, with the various temperature regimes other than in 
combined effects were examined minimum average mean values for root dry weight with (68.0, 58.0 and $43.0 \mathrm{mg}$ ) in wheat cultivar Sahar at the 15,20 and $25^{\circ} \mathrm{C}$ temperature regimes respectively.

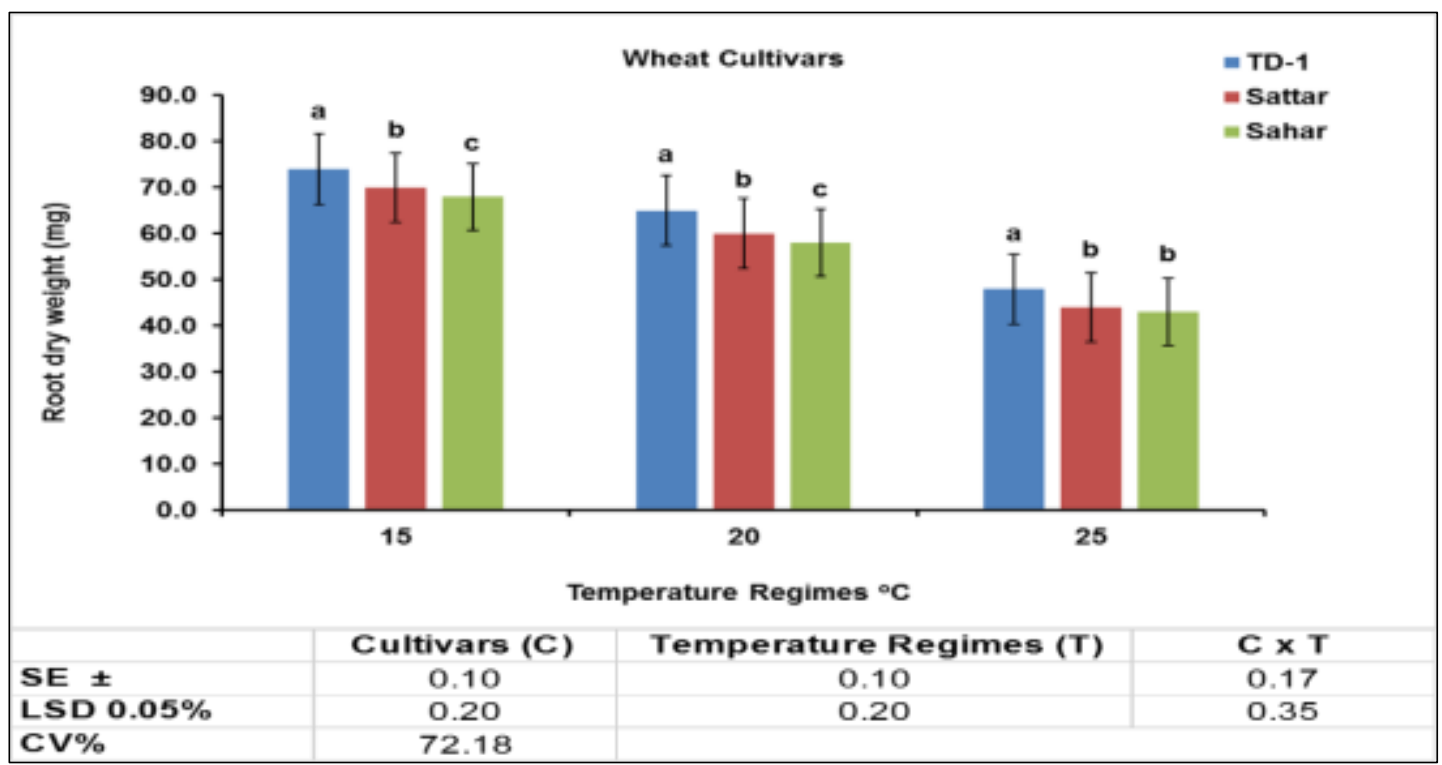

Fig.7: Root dry weight $(\mathrm{mg})$ of wheat cultivars as affected by different temperature regimes. Where TD1, Sattar, and Sahar are wheat cultivars and 15,20 , and $25{ }^{\circ} \mathrm{C}$ are temperature regimes.

Shoot moisture (\%): The experimental findings demonstrated that the shoot moisture (\%) contents of wheat cultivars are affected by the various temperature regimes shown in Figure (8).

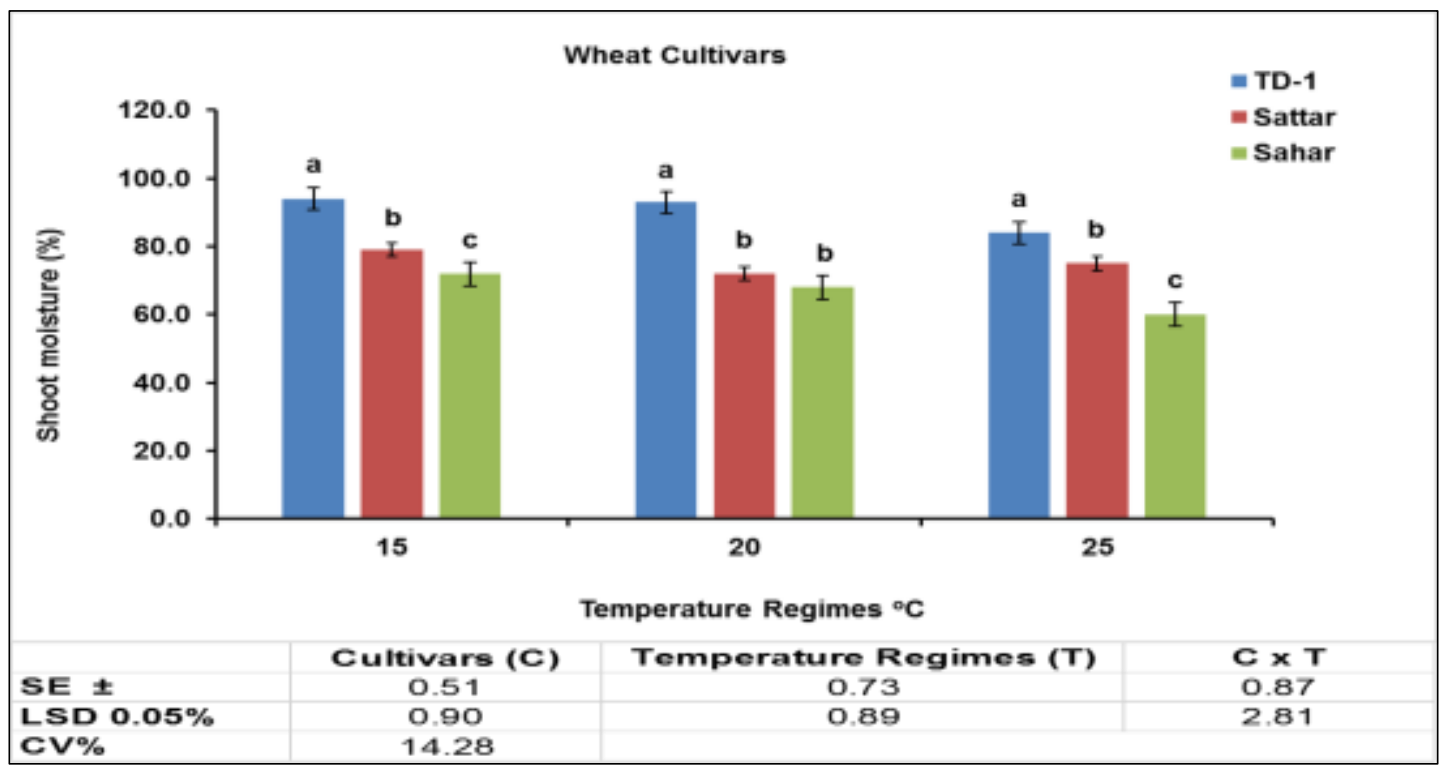

Fig.8: Shoot moisture (\%) of wheat cultivars as affected by different temperature regimes. Where TD-1, Sattar, and Sahar are wheat cultivars and 15,20 , and $25^{\circ} \mathrm{C}$ are temperature regimes. 
The statistical investigation validated that the shoot moisture $(\%)$ of different wheat cultivars under various temperature regimes statistically differed at the $\mathrm{P}<0.05$ level. The experiment results showed that at the 15,20 and $25{ }^{\circ} \mathrm{C}$ temperature regimes, shoot moisture (\%) contents consider higher average mean values with $(94.0,93.0$ and $84.0 \%)$ were recorded in the wheat cultivar TD-1 respectively. While the moderately results of the shoot moisture (\%) average mean values with the (79.0, 72.0 and $75.0 \%$ ) were indicated in wheat cultivar Sattar at the temperature regimes 15,20 and $25{ }^{\circ} \mathrm{C}$ respectively. Furthermore, in the wheat cultivar Sahar, temperature regimes as well as in the interaction the smallest shoot moisture (\%) with average mean values (72.0, 68.0 and $60.0 \%$ ) were examined at the 15,20 and $25{ }^{\circ} \mathrm{C}$ temperature regimes respectively.

Root moisture (\%): The research findings for root moisture (\%) contents of different wheat cultivars under the various temperature regimes are displayed in the Figure (9). While statistical analysis of variance was shown significant differences at the $(\mathrm{P}<0.05)$ of different wheat cultivars, in the various temperature regimes and also in the joint interactive effect with cultivars and temperature regimes were also found to be statistically significant at the $(\mathrm{P}<0.05)$ level. The significant findings supported that the highest mean average values with (68.0, 51.0 and 55.0 \%) for root moisture (\%) contents were determined in the TD-1 wheat cultivar at the 15,20 and $25{ }^{\circ} \mathrm{C}$ temperature regimes respectively. Additionally, the root moisture contents in wheat cultivar Sattar were presented by the appropriately average mean values with $(62.0,45.0$, and $42.0 \%)$ at same temperature regimes. Furthermore, in the wheat cultivar Sahar were inspected that the smallest average means values of root moisture (\%) with (46.0, 43.0, and 40.0\%) at the following temperature 15,20 , and $25^{\circ} \mathrm{C}$ regimes, respectively.

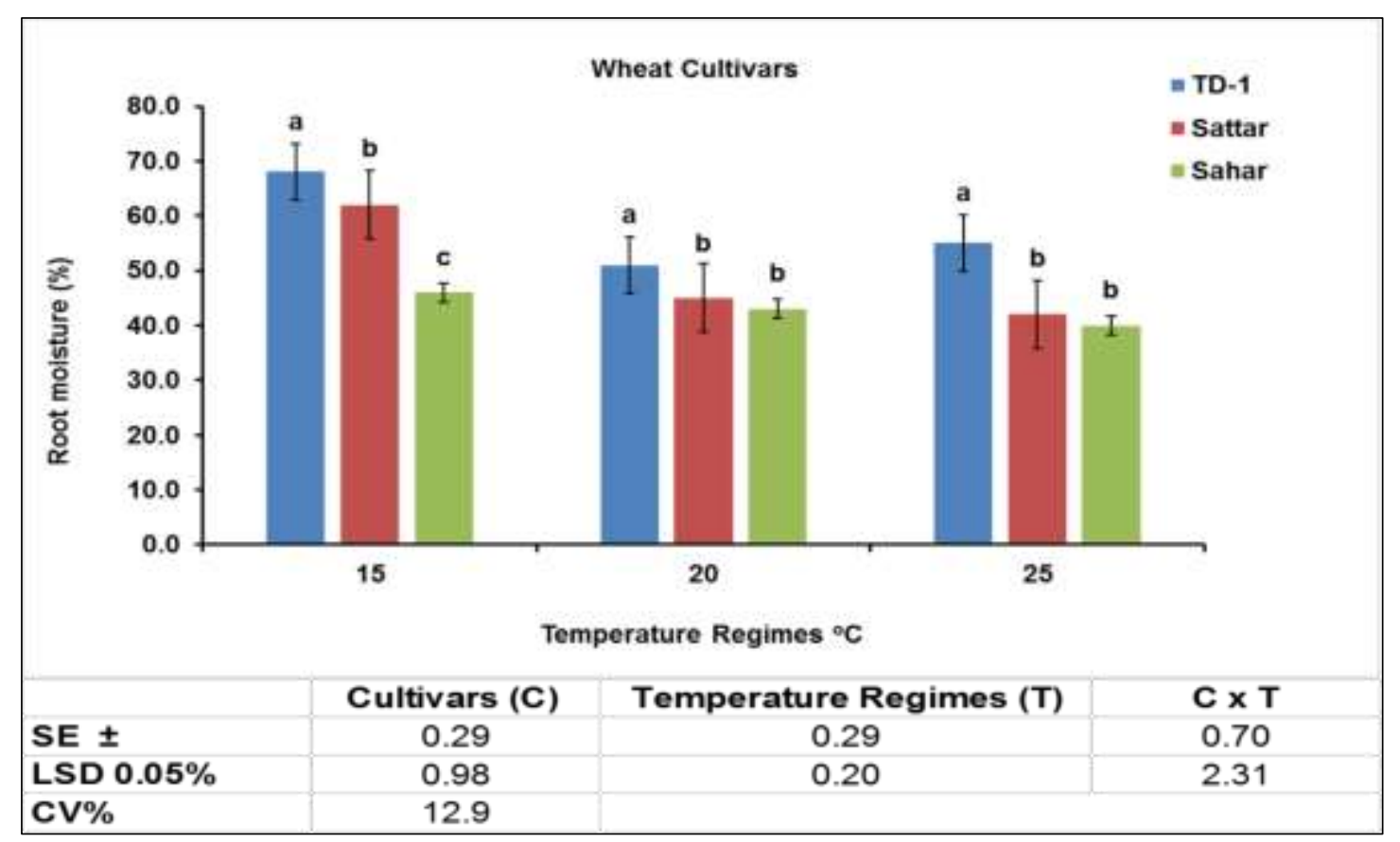

Fig.9: Root moisture (\%) of wheat cultivars as affected by different temperature regimes. Where TD1, Sattar, and Sahar are wheat cultivars and 15,20 , and $25^{\circ} \mathrm{C}$ are temperature regimes. 


\section{DISCUSION}

Temperature is a modifying factor in germination since it can influence the rate of water absorption and other substrates supply which are necessary for growth and development ${ }^{9}$. The results observed that maximum seed germination percentage ( $\mathrm{SG} \%, 81.3 \%$ ) was recorded at the temperature of $15{ }^{\circ} \mathrm{C}$ as compared to SG \% $(65.3 \%)$ was observed at $20{ }^{\circ} \mathrm{C}$, and minimum SG \% $(62.0 \%)$ was recorded at $25{ }^{\circ} \mathrm{C}$ temperature. In case of cultivars, the maximum SG \% (72.3\%) was recorded in cultivar TD-1 followed by cultivar Sattar which was observed $(68.3 \%)$ SG \% and the minimum seed germination $(68.0 \%)$ were observed in the cultivar of Sahar. The present study showed that the maximum shoot length $(18.2 \mathrm{~cm})$ was recorded at $15{ }^{\circ} \mathrm{C}$ followed by $(13.8 \mathrm{~cm})$ shoot length at $20{ }^{\circ} \mathrm{C}$ temperature and minimum shoot length $(7.5 \mathrm{~cm})$ were observed at the $25{ }^{\circ} \mathrm{C}$. In case of cultivars, the maximum shoot length $(13.5 \mathrm{~cm})$ was recorded in cultivar TD-1 followed by cultivar Sattar which was observed $(13.1 \mathrm{~cm})$ and the minimum shoot length $(12.9 \mathrm{~cm})$ was observed in the cultivar of Sahar. The influence of high temperatures on growth and development of wheat and other crops is also well documented ${ }^{5}$. Their findings are also supporting our results and explaining that the ideal temperature is very crucial at seed germination stage.

The results showed that maximum root length $(10.6 \mathrm{~cm})$ was recorded at the temperature of $15{ }^{\circ} \mathrm{C}$ as compare to $(7.9 \mathrm{~cm})$ root length was observed at the temperature of $20{ }^{\circ} \mathrm{C}$, and minimum $(5.6 \mathrm{~cm})$ root length was observed at the temperature of $25^{\circ} \mathrm{C}$. In case of cultivars, the maximum $(8.6 \mathrm{~cm})$ root length was recorded in cultivar TD-1 followed by $(7.8 \mathrm{~cm})$ in cultivars Sattar and the minimum $(7.7 \mathrm{~cm})$ root length was observed in the cultivars Sahar. The above results indicated that maximum $(976.7 \mathrm{mg})$ shoot fresh weight was recorded at the temperature of $15{ }^{\circ} \mathrm{C}$ as compared to $20{ }^{\circ} \mathrm{C}$ which was observed $(881.3$ $\mathrm{mg}$ ) shoot fresh weight and the minimum shoot fresh weight $(578.3 \mathrm{mg})$ was observed at the temperature of $25^{\circ} \mathrm{C}$. In case of cultivars, the maximum $(836.7 \mathrm{mg})$ shoot fresh weight was recorded in cultivar TD-1 as compared to Sattar which was observed $(818.0 \mathrm{mg})$ shoot fresh weight and the minimum $(781.7 \mathrm{mg})$ shoot fresh weight was observed in the cultivar Sahar. In interaction, the maximum $(1025.0 \mathrm{mg})$ shoot fresh weight was observed at $15{ }^{\circ} \mathrm{C}$ in cultivar TD-1. However, the minimum $(550.0 \mathrm{mg})$ shoot fresh weight was observed in cultivar Sattar at the temperature of $25^{\circ} \mathrm{C}$. A similar study was done by Prasad et al. ${ }^{6}$, they studied that the high-temperature damage photosynthetic membranes (thylakoids) and cause chlorophyll loss, decrease photosynthetic leaf rate, increase embryo abortion, decreased the root, shoot fresh and dry weight and ultimately lower grain number and grain yield.

Moreover, the results revealed that maximum root fresh weight $(764.0 \mathrm{mg})$ was recorded at the temperature of $15{ }^{\circ} \mathrm{C}$ as compared to $20{ }^{\circ} \mathrm{C}$ which was observed $(639.3 \mathrm{mg})$ root fresh weight, and the minimum root fresh weight $(501.0 \mathrm{mg})$ was observed at the temperature of $25{ }^{\circ} \mathrm{C}$. In case of cultivars, the maximum $(674.0 \mathrm{mg})$ root fresh weight was recorded in cultivar TD-1 as compared to Sattar which was observed $(625.0 \mathrm{mg})$ root fresh weight, and the minimum $(605.0 \mathrm{mg})$ root fresh weight was observed in the cultivars Sahar. The above results indicated that maximum $(68.0 \mathrm{mg})$ shoot dry weight was recorded at the temperature of $15{ }^{\circ} \mathrm{C}$ as compared to $20{ }^{\circ} \mathrm{C}$ which was observed $(62.0 \mathrm{mg})$ shoot dry weight and the minimum $\left(40.3 \mathrm{mg}\right.$ ) shoot dry weight was observed at the temperature of $25{ }^{\circ} \mathrm{C}$. In case of cultivars, the maximum $(62.3 \mathrm{mg})$ shoot dry weight was recorded in cultivar TD-1 as compared to Sattar who was observed $(55.3 \mathrm{mg})$ shoot dry weight and the minimum $(52.7 \mathrm{mg})$ shoot dry weight was observed in the cultivar Sahar. Similar results were found by Lobell and Ortiz-Monasterio. ${ }^{10}$, they recorded that minimum and maximum temperatures can affect seed germination, dry mass production as well as grain yield ${ }^{10}$. 
Their findings are supporting our results significantly. These effects are might be due to the loss of water and carbon dioxide $\left(\mathrm{CO}_{2}\right)$ uptake cause reduction of dry matter production pathway ${ }^{4}$.

The high temperature also affects the root dry weight many crops, including wheat cultivars. Similar results were observed in this study. The results of this study indicated that maximum root dry weight (70.7 mg) was recorded at the temperature of $15{ }^{\circ} \mathrm{C}$ as compared to $20{ }^{\circ} \mathrm{C}$ which was observed $(61.0 \mathrm{mg})$ root dry weight, and the minimum $(45.0 \mathrm{mg})$ root dry weight was observed at the temperature of $25{ }^{\circ} \mathrm{C}$. In case of cultivars, the maximum $(62.3 \mathrm{mg})$ root dry weight was recorded in cultivar TD-1 as compared to wheat cultivar Sattar who was observed $(58.0 \mathrm{mg})$ root dry weight and the minimum $(56.3 \mathrm{mg})$ root dry weight was observed in the wheat cultivar Sahar. The above results indicated that maximum (58.7\%) root moisture was recorded at the temperature of $15{ }^{\circ} \mathrm{C}$ as compared to $20{ }^{\circ} \mathrm{C}$ which was observed $(46.3 \%)$ root moisture and the minimum $(45.7 \%)$ root moisture was observed at the temperature of $25{ }^{\circ} \mathrm{C}$. In case of wheat cultivars, the maximum $(58.0 \%)$ root moisture was recorded in cultivar TD-1 as compared to Sattar which was observed $(49.7 \%)$ root moisture and the minimum $(43.0 \%)$ root moisture contents were observed in the wheat cultivar Sahar. The above results indicated that maximum $(81.7 \%)$ shoot moisture was recorded at the temperature of $15{ }^{\circ} \mathrm{C}$ as compared to $20{ }^{\circ} \mathrm{C}$ which was observed $(73.0 \%)$ shoot moisture and the minimum $(77.7 \%)$ shoot moisture was observed at the temperature of $25{ }^{\circ} \mathrm{C}$. In case of wheat cultivars, the maximum $(90.3 \%)$ shoot moisture was recorded in cultivar TD-1 as compared to Sattar which was observed $(75.3 \%)$ shoot moisture and the minimum $(66.7 \%)$ shoot moisture was observed in the cultivar of wheat cultivar Sahar. Khan et al. ${ }^{11}$ suggested that the response of different agronomical and germination traits under different temperature regimes in wheat cultivars is might be due to genetic variances with greater magnitude than environmental variances for most of the traits in plant growth from seed germination to early growth stage. Wheat cultivars showed different responses under different temperature. This showed the temperature regimes such as minimum, optimum, and maximum temperatures have various functions which totally depends on the nature of wheat cultivars either cultivar is sensitive or resistant ${ }^{4}$. The wheat growth parameters which have been studied are directly associated with temperatures. As temperature is crucial and integral factor for photosynthesis activities, and carbohydrates production. Temperature variations can alter the physiological function, water stress, decrease the metabolic activities, hormonal imbalance, and ultimate cause reduction of root, shoot growth and yield ${ }^{12-14}$.

\section{CONCLUSION}

The results are statistically significantly affected on the growth and yield traits of wheat cultivars at different temperature regimes. The present study revealed that the maximum seed germination $\%$ was recorded at $15{ }^{\circ} \mathrm{C}$ in TD-1 wheat cultivar compared to other cultivars and temperature. These differences could be due to their genetic variations of these wheat cultivars. These results are suggesting that the optimum temperature is vital for the better seed germination and early growth traits for the wheat cultivar. This study will pave the new ways to the scientific community to work more at molecular and physiological basis to search out the real role of temperature for the better growth and yield for the wheat crop. 


\section{ACKNOWLEDGMENT}

We are thankful to the department of agronomy of Sindh Agriculture University, Tandojam, Sindh Pakistan for providing us basic research facilities. We also extended our thanks to a worthy supervisor, who has given us the kind suggestions and guidance to complete this research.

\section{CONFLICT OF INTEREST}

All author revised the manuscript, and there is no conflict of interest found in this study.

\section{REFERENCE}

1. Sharma, B.S. Tyagi, G. Singh, K. Venkatesh, O.P. Gupta, Enhancing wheat production- a global perspective. Indian Journal of Agricultural Sciences, 2015, 85(1): 3-13.

2. Government of Pakistan. Economic Survey of Pakistan. Ministry of Food, Agriculture, and Livestock, Government of Pakistan, Statistics Division, Islamabad. 2016.

3. J.L. Hatfield, J.H. Prueger, Agro-ecology: Implications for Plant Response to Climate Change. In: Crop adaptation to climate change, (Eds.), Wiley-Blackwell, West Sussex, United Kingdome, 2011. Pp. 27-43.

4. J.R. Porter, M. Gawith, Temperatures and the growth and development of wheat: a review. European Journal of Agronomy, 1999, 10 (1): 23-36

5. T.R. Wheeler, P.Q. Craufurd, R.H. Ellis, J.R. Porter, P.V. Prasad, Temperature variability and the yield of annual crops. Agriculture, Ecosystems \& Environment, 2000, 82 (1-3): 159-167.

6. P.V. Prasad, K.J. Boote, L.H. Allen Jr, Adverse high temperature effects on pollen viability, seed-set, seed yield, and harvest index of grain sorghum (Sorghum bicolor L.) are more severe at elevated carbon dioxide due to higher tissue temperatures. Agricultural and forest meteorology, 2006, 139 (3-4): 237-251.

7. J. Larkindale, M. Mishkind, E. Vierling, Plant responses to high temperature. In: Plant Abiotic Stress. (Eds.) Blackwell, Oxford, United Kingdome, 2005. Pp. 100-144.

8. B. Ehdaie, G.A. Alloush, M.A. Madore, J.G. Waines, Genotypic variation for stem reserves and mobilization in wheat. Crop science, 2006, 46 (5): 2093-2103.

9. J. Essemine, S. Ammar, N. Jbir S. Bouzid, Sensitivity of two Wheat species seeds (Triticum durum L., variety Karim and Triticum aestivum L., Variety Salambo) to heat constraint during germination. Pakistan Journal of Biological Sciences, 2007, 10 (21): 3762-3768.

10. D.B. Lobell, J. I. Ortiz-Monasterio. Impact of day versus night temperature on spring wheat yields: Agronomy journal, 2007, 99 (2): 469-477.

11. Khan, I.H. Khalil, Genetic parameters for yield traits in wheat under irrigated and rainfed environments. Sarhad Journal of Agriculture, 2007, 23 (4): 1016-4383. 
12. A.J. Challinor, J. Watson, D.B. Lobell, S.M. Howden, D.R. Smith, N. Chhetri, A meta-analysis of crop yield under climate change and adaptation. Nature Climate Change, 2014, 4 (4): 287291.

13. M. Hasanuzzaman, K. Nahar, M. Alam, R. RoyChowdhury, M. Fujita, Physiological, biochemical, and molecular mechanisms of heat stress tolerance in plants. International journal of molecular sciences. 2013, 14 (5): 9643-9684.

14. M. Farooq, H. Bramley, J.A. Palta, K.H. Siddique, Heat stress in wheat during reproductive and grain-filling phases. Critical Reviews in Plant Sciences, 2011, 30 (6): 491-507.

\section{* Corresponding author: Maqsood Ahmed Khaskheli}

State Key Laboratory of Rice Biology, China National Rice Research Institute, Hangzhou, 311400, Zhejiang, China.

Email: khaskheli.maqsood89@gmail.com

Online publication Date: 05.10.2019. 